\title{
EXERGY ANALYSIS OF PRE-COOLED LINDE SYSTEM FOR LIQUEFACTION OF GASES FOR IMPROVING PERFORMANCE OF LINDE BASED CRYOGENICS SYSTEMS
}

\author{
Devender Kumar ${ }^{1}$, R.S Mishra ${ }^{2}$ \\ ${ }^{1}$ Research Scholar, Mechanical Department, Delhi Technological University, Shahabad, Delhi \\ ${ }^{2}$ Professor, Mechanical Department, Delhi Technological University, Shahabad, Delhi
}

\begin{abstract}
Cryogenic temperature generally temperature below the $-150^{\circ} \mathrm{C}$. Various number of gases are liquefy by using very first Linde Hampson cycle but due to inefficiency of system output of liquefaction mass is very low as compared to expanses. Linde Pre-cooled system is designed to meet the gap in the basic Linde system. The output as well as the second law efficiency of Linde pre-cooled system is more than the basic Linde system. A complete thermo -analysis of pre-cooled Linde system is carried out and various results are predicted. The effect of some various parameters like refrigerant mass flow ratio and compressor pressure on system with six different gases is studied by applying computational numerical technique. Effect of these parameters on system conclude that the system work good near 200 bar pressure and refrigerant mass flow ratio of 0.03 is suitable for system showing high second law efficiency and Liquefaction mass ratio and low work done per liquefaction mass ratio.
\end{abstract}

Keywords: Thermodynamics analysis, pre-cooled Linde system, refrigerant mass flow ratio, second law efficiency

\section{INTRODUCTION}

Cryogenic industry is a very vast business industry touching almost every field of science like space, Medical science, BioTechnology etc. Various methods are present to achieve cryogenic temperature, but economical still a challenge. Exergy analysis of system provides a tool to find out the losses in system and give a chance to achieve economical challenge. In past history various method are invented to get high exergy efficiency. Liquefaction is currently done in more complex cycles, which require about $1080 \mathrm{~kJ}$ of energy for each liquefied $\mathrm{kg}$ [1].Linde cycle is simplest form of air liquefaction system but less second law efficiency make it economical inefficient system. Liquefaction plants are rather complicated with numerous components interacting with each other and consume a large amount of process energy, it is vital to develop efficient liquefaction processes for improving the overall system performance and economic competitiveness [2]. Various research and different method are employed to increase efficiency of cryo system. Second law efficiency are very low in all system, it value ranging from $3 \%$ to $23 \%$ for most of systems. Advance technology like different cryo fluid includes nano one (nano fluid and nano lubricants) is also tried to reduces the losses. Ceramic technology is also used in separator to increase the high output with less losses. It is noticed that the evaporating and condensing temperatures put a strong effects on the exergy losses in the evaporator, condenser, second law of efficiency and COP of the cycle but little effects on the exergy losses in the compressor and the expansion valve. The second law efficiency and the COP increases, and the total exergy loss decreases with decreasing temperature difference between the evaporator and refrigerated space and between the condenser and outside air [3] and if advance technology like nano fluid include it noticed that Nano fluid and Nano lubricant cause to reduce the exergy losses in the compressor indirectly [4].

\section{THERMO ANALYSIS OF PRE-COOLED LINDE} SYSTEM FOR LIQUEFICATION OF GASES:

First and second law computational numerical analysis of Precooled Linde system is done for detail studies for optimized used of system .Various parameters like refrigerant mass flow ratio and compressor pressure is varies for detailed study of system .Pre-cooled Linde Hampson system is advanced stage old simple Linde Hampson system .In this system vapour compression evaporator having R134 a refrigerant is taken as additional equipment to fill the gap of simple Linde system. In Fig.1.1 the detail block diagram of Pre-cooled Linde system is shown and Fig 1.2 show T-S diagram of Pre-cooled Linde system. Vapour compression system lower down the temperature of gases coming through the compressor which is desirable for better performance of system. 

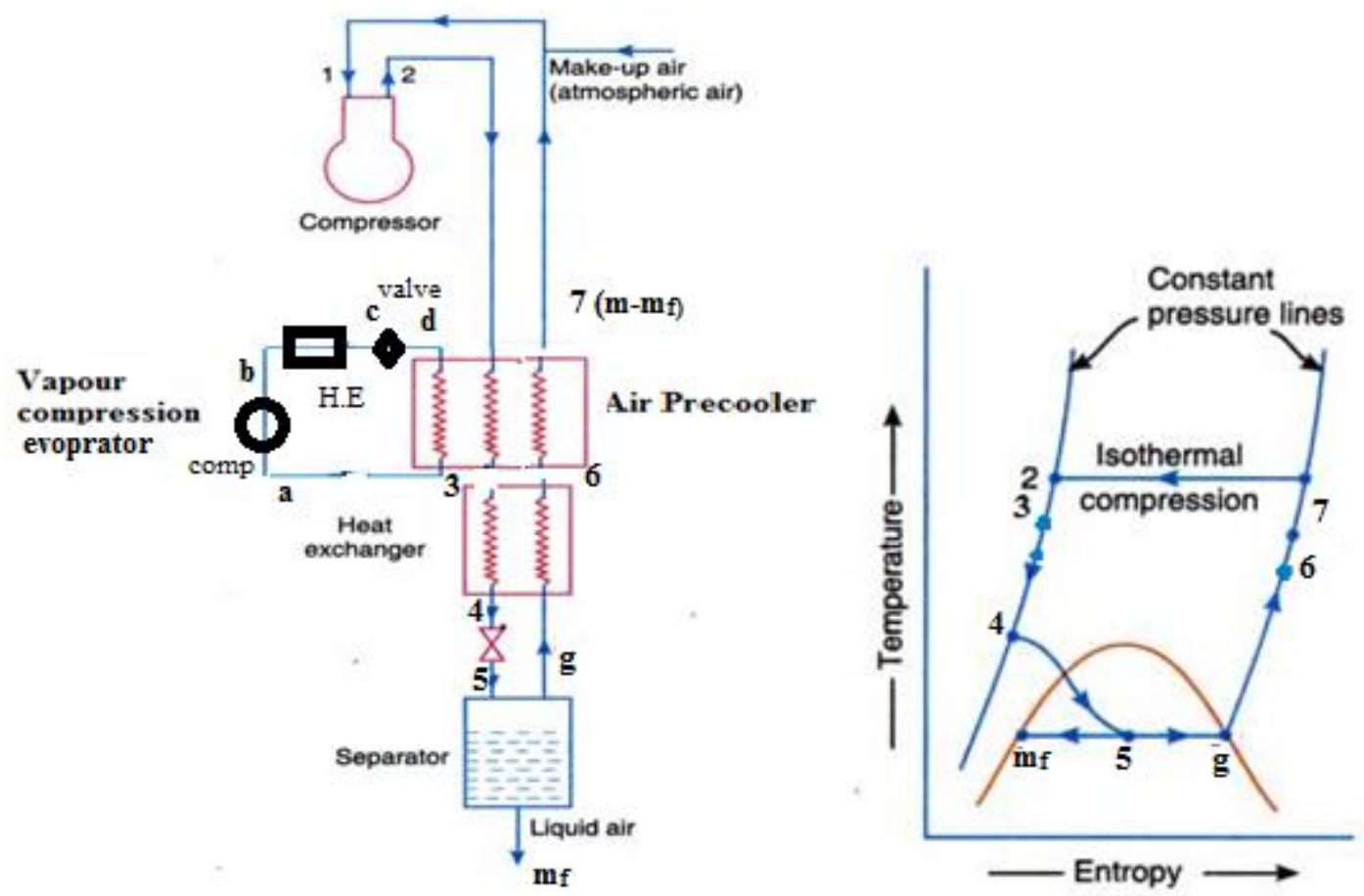

Fig 1.1:Pre-Cooled Linde sytem

Fig 1.2 T-S diagram of pre-cooled Linde system

"Energy Balance by First Law"

$$
\begin{gathered}
m_{r} * h_{d}+m * h_{2}=m_{r} * h_{a}+ \\
\frac{m_{f}}{m}=\frac{h_{1}-h_{2}}{h_{1}-h_{f}}+r * \frac{h_{a}-h_{d}}{h_{1}-h_{f}} \\
y=\frac{m_{f}}{m}
\end{gathered}
$$

"Control Volume having Heat exchanger, Joule-Thomson valve, Separator"

$$
\begin{aligned}
& m * h_{3}=m_{f} * h_{f}+\left(m-m_{f}\right) * h_{6}(4) \\
& y_{\max }=\frac{h_{6}-h_{3}}{h_{6}-h_{f}}
\end{aligned}
$$

$$
\begin{gathered}
E_{\text {out }}=m * h_{2}-Q_{R} \\
Q_{R}=m * T_{1} *\left(S_{2}-S_{1}\right)
\end{gathered}
$$

"Compressor work of ref system"

$$
\begin{aligned}
& m_{r} * h_{a}-W_{c 2}=m_{r} * h_{b} \\
& -\frac{W_{\text {total }}}{m_{f}}=Z
\end{aligned}
$$

$$
\begin{aligned}
-\frac{W_{\text {total }}}{m}= & T_{1} *\left(s_{1}-s_{2}\right)-\left(h_{1}-h_{2}\right)+r *\left(h_{b}-h_{a}\right) \\
-\frac{W_{i}}{m}= & T_{1} *\left(s_{1}-s_{f}\right)-\left(h_{1}-h_{f}\right) \\
& -\frac{W_{i}}{m}=K
\end{aligned}
$$

"Work"

$$
W_{\text {total }}=W_{c 1}+W_{c 2}
$$

$$
\text { COP }=\frac{\left(h_{1}-h_{f}\right)}{W_{\text {total }}}
$$

"Compressor work of liquefaction system"

$$
\eta_{2 n d}(\%)=\frac{\left(h_{f}-h_{1}\right)-T_{0} *\left(s_{f}-s_{1}\right)}{W_{\text {total }} * m_{f}} * 100
$$

$$
\begin{gathered}
E_{\text {in }}=E_{\text {out }} \\
E_{\text {in }}=m * h_{1}-W_{c 1}
\end{gathered}
$$




\section{Refrigerant Properties:}

Table 1

\begin{tabular}{|l|l|}
\hline $\mathrm{P}_{\mathrm{a}}$ & 1.013 \\
\hline $\mathrm{P}_{\mathrm{b}}$ & 10.013 \\
\hline $\mathrm{P}_{\mathrm{c}}$ & 10.013 \\
\hline $\mathrm{T}_{\mathrm{a}}$ & 300 \\
\hline $\mathrm{T}_{\mathrm{b}}$ & 373 \\
\hline $\mathrm{T}_{\mathrm{c}}$ & 300 \\
\hline $\mathrm{h}_{\mathrm{a}}$ & 278 \\
\hline $\mathrm{h}_{\mathrm{c}}$ & 89.07 \\
\hline $\mathrm{T}_{\mathrm{d}}$ & 247.1 \\
\hline
\end{tabular}

\section{RESULTS AND DISCUSSION:}

On the basis of above equations and applying computational numerical technique following result about pre-cooled Linde system considering six different gases is studied. Fig 2 show variation in work done per liquefaction mass of with compressor pressure, there is sharp decrease in work done up to 200 bar but after that the decrease in work done is slow become nearly constant up to 400 bar but after that, increment in work start with further increase in pressure. In all six gases fluorine show very high decrement in work done as compare to other gases with increasing compressor pressure. Fig 3 show the yield mass rate variation with compressor pressure, up to 200 bar the yield mass is directly proportional to compressor pressure but beyond 200 bar pressure the increment in yield mass rate of liquefaction is very small. Oxygen gas other than other gases show very different behavior because high yield rate as compared to other gases.Fig.4 show variation in work done per liquefaction mass with refrigerant mass flow ratio, the work done is very less affected by the increasing refrigerant flow rate but there is increment in work done with increment in refrigerant mass flow ratio. Fig 5 show there is decrease in second law efficiency with increase in refrigerant mass flow ratio. Whereas Fig 6 show increase in second law efficiency with compressor pressure up to 200 bar for all six gases but if there is increase in compressor pressure beyond 200,the second law efficiency start decreasing for gases except argon ,oxygen ,fluorine, they show continuous but slow increment in second law efficiency .Fig 7 show change in COP with increasing refrigerant mass flow ratio is almost constant whereas Fig 8 show decrease in COP with increasing compressor pressure.

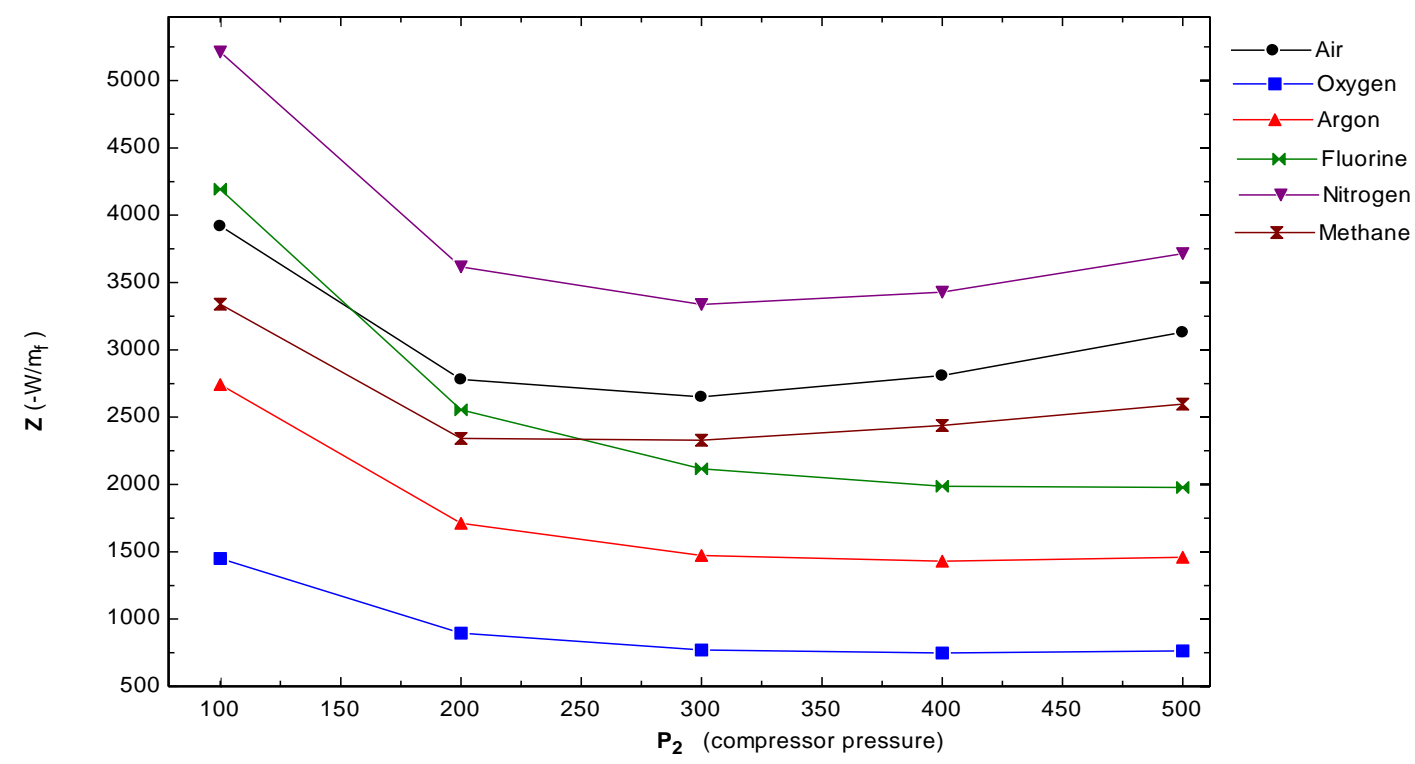

Fig: 2 Variation of work done per liquefaction with the compressor pressure 


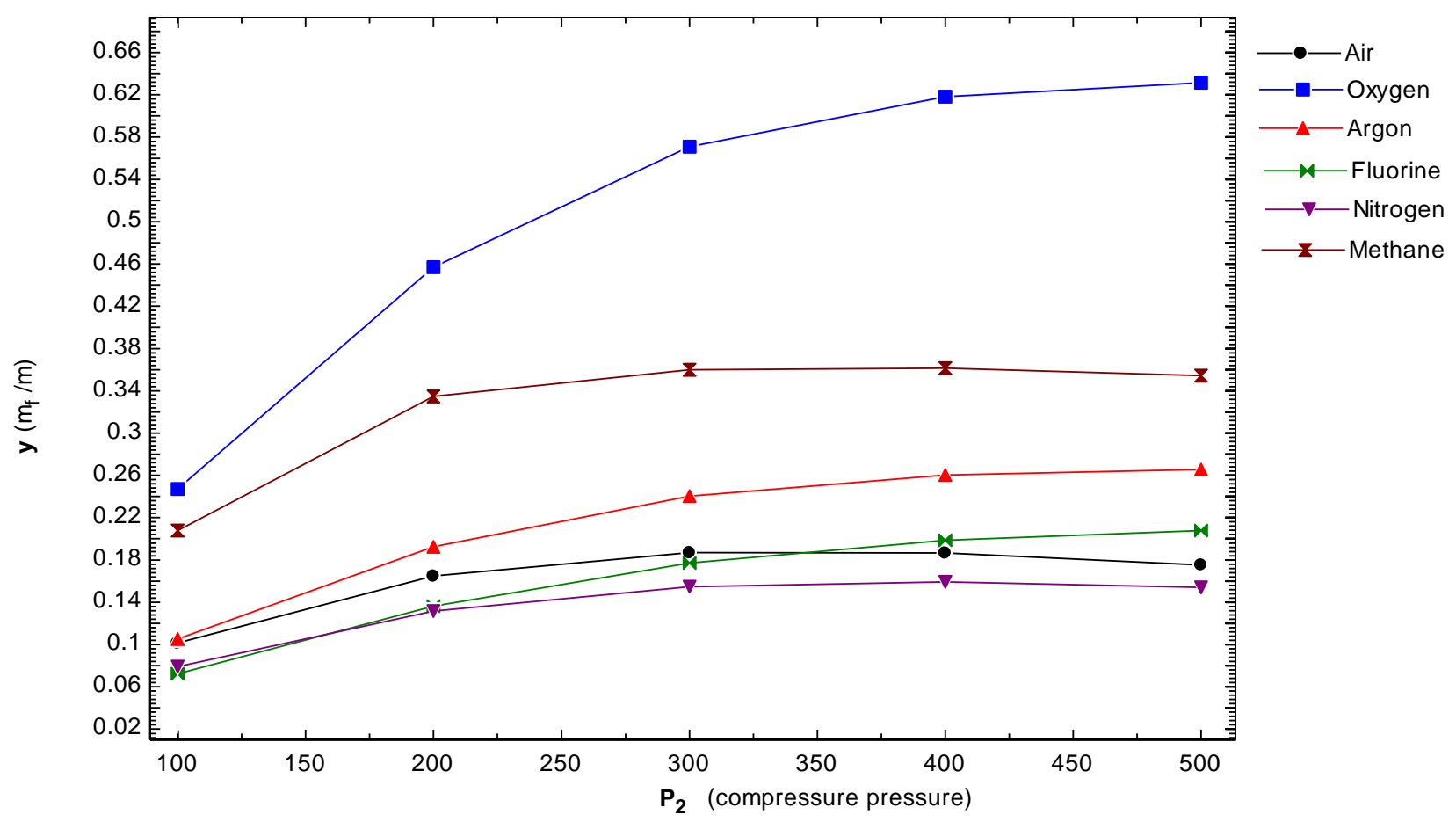

Fig: 3 Variation of liquefaction mass ratio with the compressor pressure

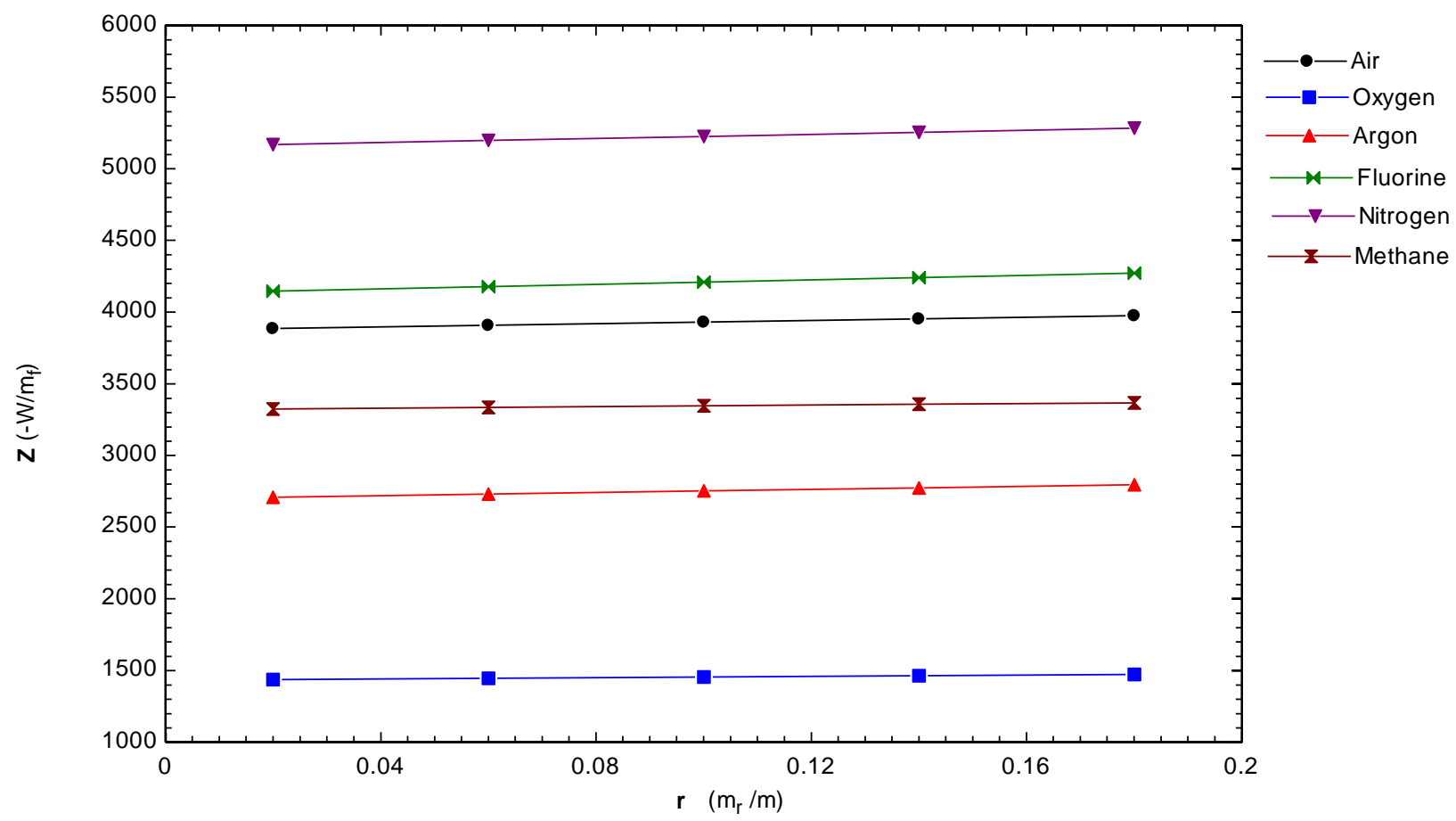

Fig: 4 Variation of work done per liquefaction mass with the refrigerant mass flow rate 


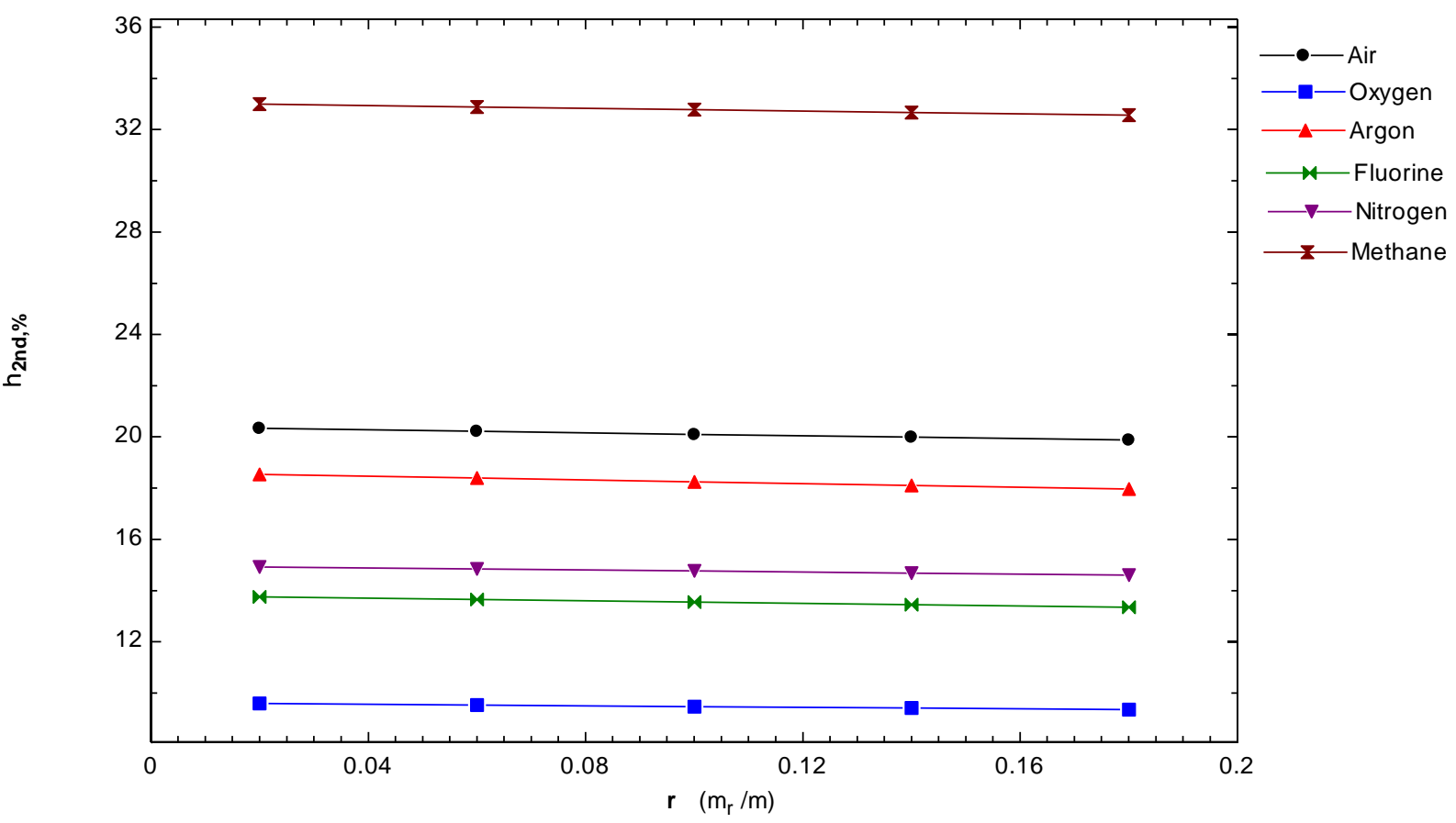

Fig: 5 Variation in second law efficiency with refrigerant mass flow rate

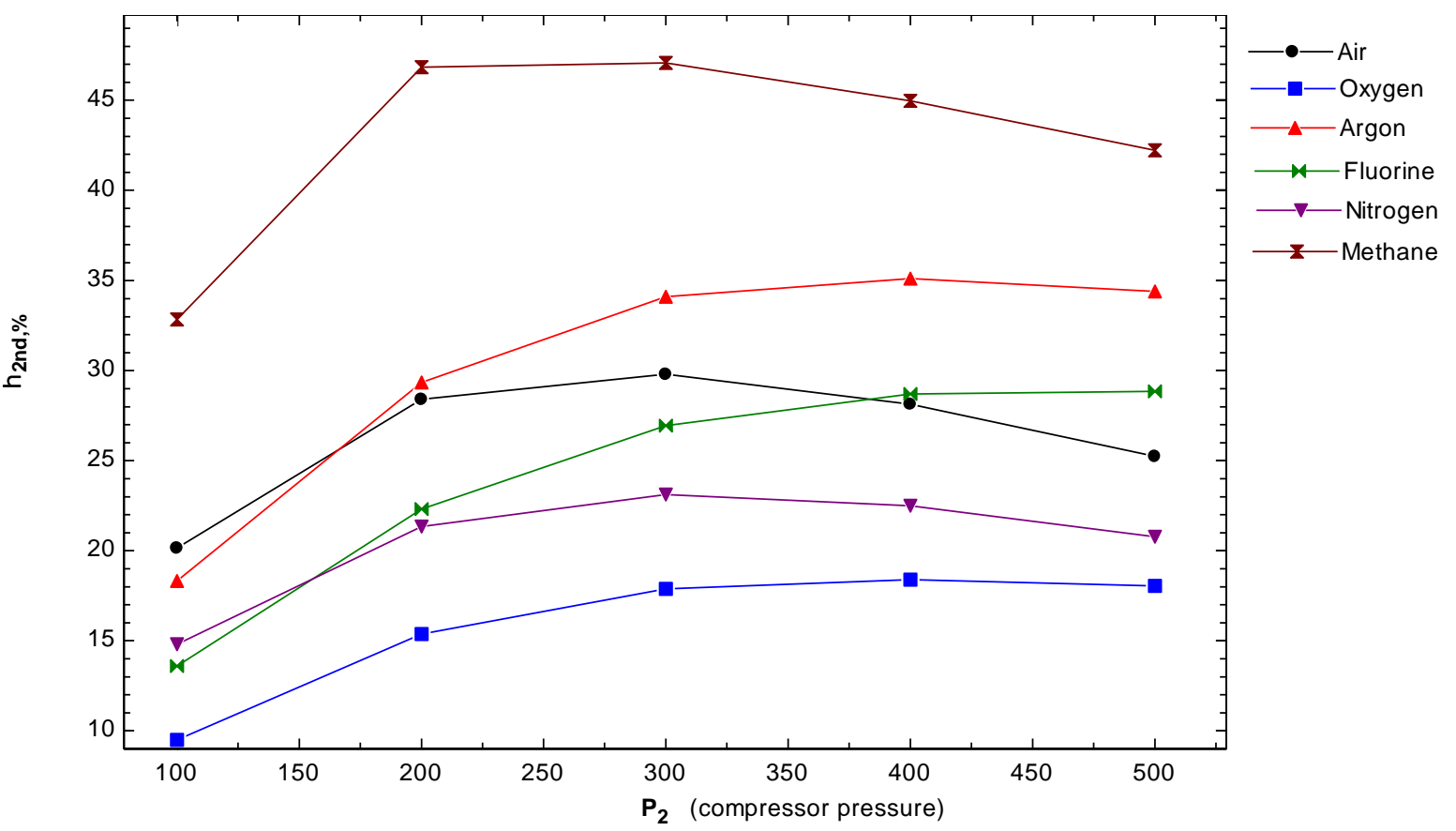

Fig: 6 Variation in second law efficiency with the compressor pressure 


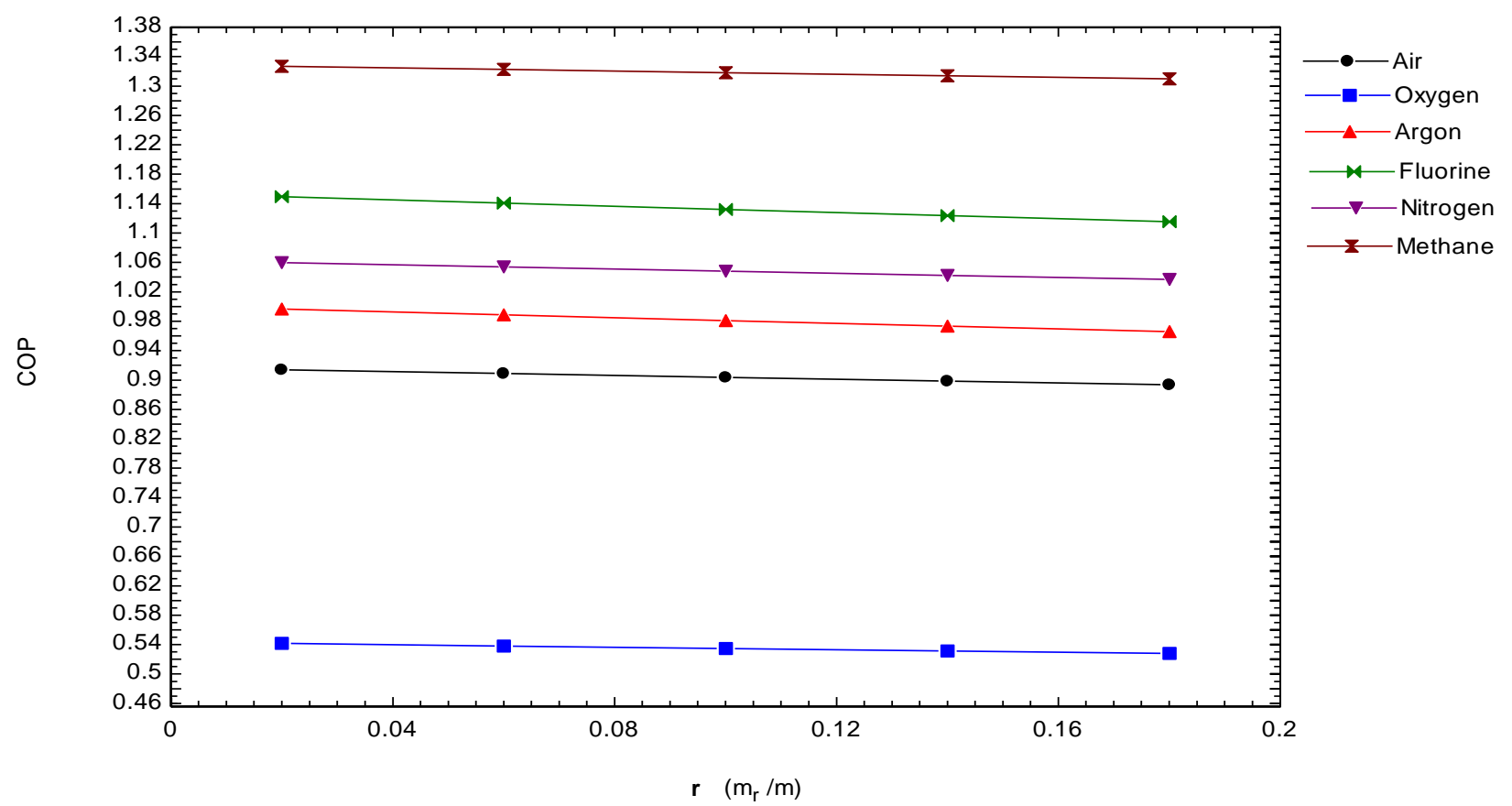

Fig: 7 Variation in COP with the refrigerant mass flow rate

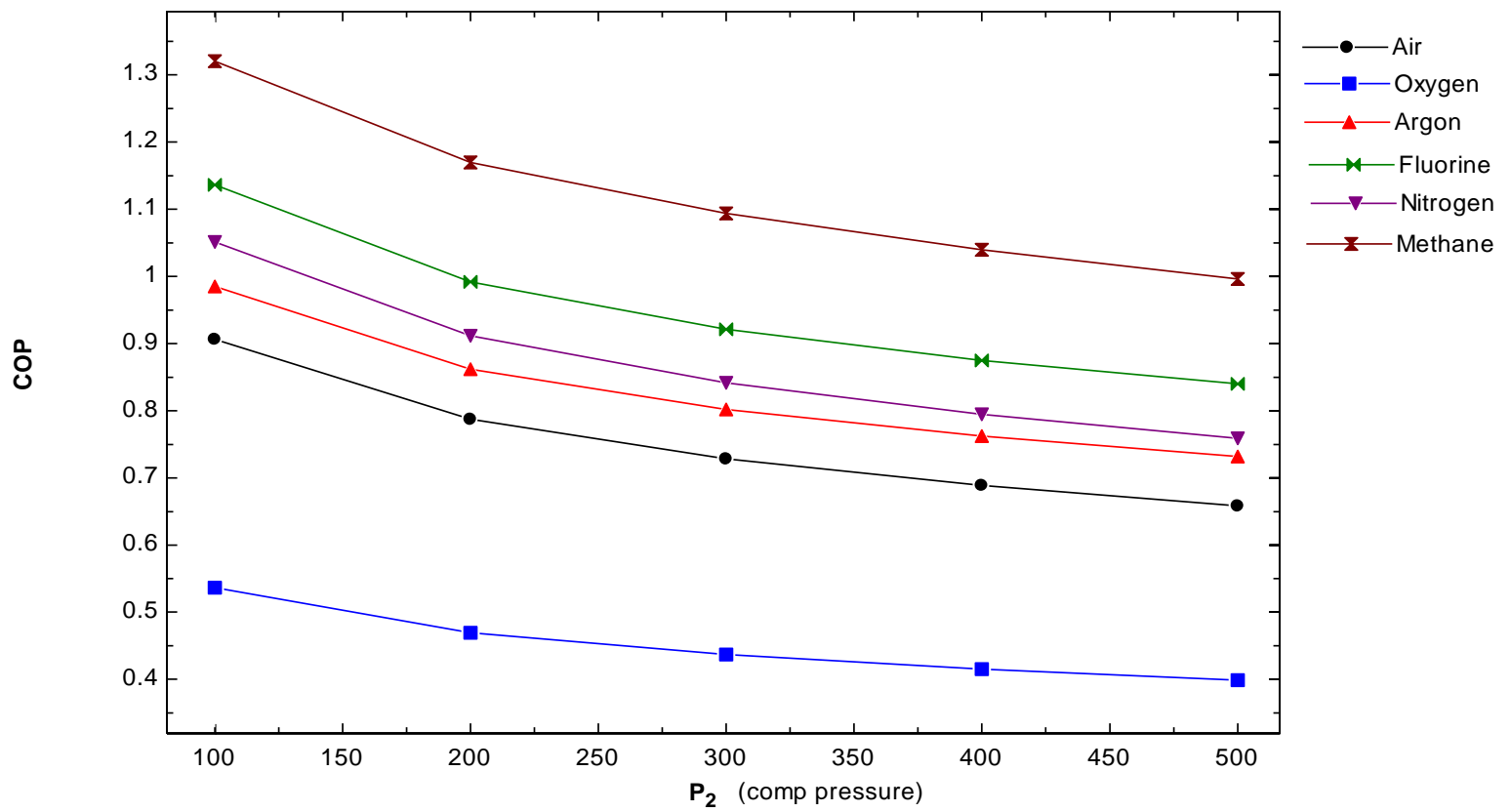

Fig: 8 Variation in COP with the compressor pressure

\section{CONCLUSIONS}

1) Compressor pressure up to 200 bar pressure show positive result ,up to this pressure second law efficiency and liquefaction mass ratio is show increment but after crossing this pressure rate of increasing the second law efficiency is deteriorate, and a significant dip in efficiency notice after 300 bar pressure whereas liquefaction mass ratio except oxygen show a constant extraction with negligible increment.

2) Refrigerant mass ratio also effect the second efficiency , COP show decreasing in nature while Work done per liquefaction mass of system show increasing in nature with increase in refrigerant mass flow ratio. 


\section{REFRENCES}

[1]. W.F. Castle, Air separation and liquefaction: recent developments and prospects for the beginning of the new millennium, International Journal of Refrigeration-Revue Internationale Du Froid 25 (Jan. 2002) 158-172.

[2]. Kanoglu M. Cryogenic turbine efficiencies. Exergy, Int J 2001;1:202-8.

[3]. Recep Yumrutaş, Mehmet Kunduz, Mehmet Kanoğlu, Exergy analysis of vapor compression refrigeration systems, Exergy, An International Journal, Volume 2, Issue 4, 2002, Pages 266-272, ISSN 1164-0235

[4]. J.U. Ahamed, R. Saidur, H.H. Masjuki, A review on exergy analysis of vapor compression refrigeration system, Renewable and Sustainable Energy Reviews, Volume 15, Issue 3, April 2011, Pages 1593-1600, ISSN 1364-0321.

\section{NOMENCLATURE}

$m_{r}=$ mass flow rate of refrigerant

$\mathrm{m}=$ mass flow rate of gas

$m_{f}=$ Liquefaction mass

$h=$ Enthalpy

$\mathrm{s}=$ Entropy

$\mathrm{X}=$ Dryness fraction

$\mathrm{T}=$ temperature

$\mathrm{P}=$ Pressure

$\eta_{2 \text { nd law }}=$ Second law efficiency

$\mathrm{C}=$ Specific heat capacity fluid or gas

$W_{\text {total }}=$ Total Work of compression

$W_{c 1}=$ Compressor work of system

$W_{c 1}=$ Compressor work of vapour compression system

$\mathrm{Y}=$ liquefaction mass flow ratio

$\mathrm{E}=$ Energy

$\mathrm{R}=$ Refrigerant 